\title{
Persistent hyperinsulinaemic hypoglycaemia in children with Rubinstein-Taybi syndrome
}

\author{
Alena Welters ${ }^{1}$, Ranna El-Khairi², Antonia Dastamani², Nadine Bachmann ${ }^{3}$, Carsten Bergmann ${ }^{3}$, Clare Gilbert ${ }^{2}$, \\ Emma Clement ${ }^{4}$, Jane A Hurst ${ }^{4}$, Nada Quercia,5, Jonathan D Wasserman7, Thomas Meissner ${ }^{1}$, Pratik Shah²,8 and \\ Sebastian Kummer ${ }^{1}$
}

${ }^{1}$ Department of General Paediatrics, Neonatology and Paediatric Cardiology, Medical Faculty, University Children's Hospital Düsseldorf, Düsseldorf, Germany, ${ }^{2}$ Endocrinology Department, Great Ormond Street Hospital for Children NHS Foundation Trust, London, UK, ${ }^{3}$ Center for Human Genetics, Bioscientia, Ingelheim, Germany, ${ }^{4}$ Department of Clinical Genetics, Great Ormond Street Hospital for Children NHS Foundation Trust, London, UK, ${ }^{5}$ Department of Genetic Counselling, The Hospital for Sick Children, Toronto, Canada, ${ }^{6}$ Department of Molecular Genetics, University of Toronto, Toronto, Canada, ${ }^{7}$ Division of Endocrinology, The Hospital for Sick Children, Toronto, Canada, and ${ }^{8}$ Genetics and Genomic Medicine Programme, Genetics and Epigenetics in Health and Disease Section, UCL Great Ormond Street Institute of Child Health, London, UK

Correspondence should be addressed to P Shah or S Kummer Email

Pratik.Shah@gosh.nhs.uk or sebastian.kummer@med. uni-duesseldorf.de

\begin{abstract}
Objective: Genetic aetiology remains unknown in up to $50 \%$ of patients with persistent hyperinsulinaemic hypoglycaemia $(\mathrm{HH})$. Several syndromes are associated with $\mathrm{HH}$. We report Rubinstein-Taybi syndrome (RSTS) as one of the possible causes of persistent $\mathrm{HH}$. Early diagnosis and treatment of $\mathrm{HH}$ is crucial to prevent hypoglycaemic brain injury.

Design: Four RSTS patients with $\mathrm{HH}$ were retrospectively analysed.

Methods: Genetic investigations included next-generation sequencing-based gene panels and exome sequencing. Clinical characteristics, metabolic profile during hypoglycaemia and treatment were reviewed.

Results: Disease-related EP300 or CREBBP variants were found in all patients, no pathogenic variants were found in a panel of genes associated with non-syndromic HH. Two patients had classic manifestations of RSTS, three had choanal atresia or stenosis. Diagnosis of $\mathrm{HH}$ varied from 1 day to 18 months of age. One patient was unresponsive to treatment with diazoxide, octreotide and nifedipine, but responded to sirolimus. All required gastrostomy feeding. Conclusions: Given the rarity of RSTS (1:125 000) and HH (1:50 000), our observations indicate an association between these two conditions. We therefore recommend that clinicians should be vigilant in screening for $\mathrm{HH}$ in symptomatic infants with RSTS. In children with an apparent syndromic form of HH, RSTS should be considered in the differential diagnosis.
\end{abstract}

\section{Introduction}

Hyperinsulinaemic hypoglycaemia $(\mathrm{HH})$ is a heterogeneous disorder characterized by recurrent episodes of hypoglycaemia due to the dysregulated release of insulin from pancreatic beta cells despite low blood glucose concentrations (1). Although a rare disorder, $\mathrm{HH}$ is the most common form of persistent hypoglycaemia in the neonatal period and early infancy (2).
Recurrent hypoglycaemic insults to the developing brain are associated with serious lifelong complications such as permanent brain injury and seizures $(3,4,5)$. Therefore, early recognition and treatment of $\mathrm{HH}$ is the cornerstone for improving neurodevelopmental outcomes (6). HH represents a group of clinically, genetically and morphologically heterogeneous disorders. It can be

Published by Bioscientifica Ltd. 
caused by pathogenic variants in key genes regulating insulin secretion but has also been reported as a feature in at least 20 different rare genetic syndromes, which include overgrowth syndromes such as Beckwith-Wiedemann syndrome (BWS) and Sotos syndrome, postnatal growth failure syndromes such as Costello and Kabuki syndrome, congenital disorders of glycosylation and chromosome abnormalities such as Turner syndrome and Patau syndrome $(7,8,9,10)$. The complexity of some syndromic conditions may lead to difficulty in recognising a co-existing diagnosis of HH. This may delay the diagnosis of $\mathrm{HH}$ and further impair the neurodevelopmental outcomes of these children. Moreover, an early genetic diagnosis is important to guide medical management and provide information on prognosis and recurrence risk.

We here describe the association of Rubinstein-Taybi syndrome (RSTS) and persistent HH, and systematically summarize the clinical course of four affected patients. RSTS is a rare developmental disorder characterized by postnatal growth deficiency, microcephaly, typical facial appearance, distal limb abnormalities and a broad range of cognitive impairment. Comorbidities such as cardiovascular or urinary tract anomalies and epilepsy may be present in up to $30 \%$ of RSTS patients (11). Pathogenic variants in two genes are known to cause RSTS, i.e. those of the cAMP response element-binding protein (CREB)-binding protein (CREBBP-encoding $\mathrm{CBP}$ ) and of E1A-binding protein P300 (EP300-encoding P300). The majority of cases (60-70\%) are caused by haploinsufficiency of the CREBBP gene. Heterozygous variants disrupting the paralogous gene $E P 300$ are found in up to $10 \%$ of patients. The genetic cause is unknown in approximately $20-30 \%$ of cases $(11,12,13,14)$. Although single reports of hypoglycaemia in RSTS patients have been published, RSTS has not yet been recognized as a syndromic cause of persistent $\mathrm{HH}(15,16,17)$. Wyatt et al. reported a case of transient $\mathrm{HH}$ in a small for gestational age (SGA) newborn with RSTS that required a glucose infusion at twice the normal endogenous glucose production rate of SGA infants to maintain euglycemia. A genetic diagnosis for this patient is not available. More recently, Lopez et al. and Costain et al. reported on individuals with RSTS and $\mathrm{HH}$ due to pathogenic variants in EP300 (deletion of exons 12-21 of EP300; heterozygous de novo missense variant in the HAT domain of EP300).

We review the clinical course and genetic findings of four RSTS patients with $\mathrm{HH}$, providing additional information on the clinical characteristics and metabolic phenotype of these patients and increasing the evidence for an association between RSTS and HH.

\section{Patients and methods}

Four patients with genetically confirmed RSTS and $\mathrm{HH}$ were retrospectively analysed. Written informed consent for publication of their clinical details was obtained from all patients or their respective guardians. Genetic investigations were either targeted for pathogenic variants in EP3OO and CREBBP when RSTS was clinically suspected or untargeted as part of the deciphering developmental disorders (DDD) study when developmental delay was the predominant feature. When $\mathrm{HH}$ and/or other clinical features were prevailing and targeted testing for specific syndromes was negative, next-generation sequencing (NGS)-based gene panels or exome sequencing were applied. Pathogenic variants in genes associated with congenital hyperinsulinism $(\mathrm{CHI})$ were excluded in all cases other than case 2 where targeted testing of $C R E B B P$ was arranged due to the clinical suspicion of RSTS. Sequence variants were classified according to ACMG criteria (18). Metabolic profiling included the measurement of insulin and c-peptide, free fatty acids and blood or urinary ketones during hypoglycaemia $\leq 2.7 \mathrm{mmol} / \mathrm{L}$. Hypoglycaemia was defined as hypoketotic hypoglycaemia when betahydroxybutyrate level was $<1.8 \mathrm{mmol} / \mathrm{L}$ or urine ketones were negative. Low free fatty acids (FFA) were defined as FFA $<1.7 \mathrm{mmol} / \mathrm{L}$ (19). Initial glucose requirement is defined as the amount of carbohydrates initially required to prevent hypoglycaemia $<3.5 \mathrm{mmol} / \mathrm{L}$.

\section{Results}

Clinical characteristics, metabolic profile, genetic investigations and treatment regime of all individuals are summarized in Table 1.

\section{Case 1}

Individual 1 (P1) was born at 38-weeks gestation, with a birth weight of $2600 \mathrm{~g}$ ( -1.2 SDS). She had subtle facial features out of keeping for age and ethnicity but not at that time suggestive of an underlying syndromic diagnosis. Other clinical features included bilateral choanal atresia requiring nasal stent insertion in the neonatal period, developmental delay and gastro-oesophageal reflux disease (GORD) with unsafe swallow resulting in silent micro-aspirations. She also had episodes of tachycardia and bradycardia with normal sinus rhythm on 24-h ECG recordings and small pericardial effusion with structurally normal heart on echocardiogram. MRI brain 
Table 1 Clinical characteristics, metabolic profile, genetic investigations and treatment regime of four RSTS patients with persistent $\mathrm{HH}$.

\begin{tabular}{|c|c|}
\hline & Patient 1 \\
\hline Gestational age (w) & 38 \\
\hline Birth weight (g) & 2600 \\
\hline Sex & Female \\
\hline Dysmorphic features & $\begin{array}{l}\text { mild non-specific } \\
\text { dysmorphic features }\end{array}$ \\
\hline Other clinical features & $\begin{array}{l}\text { Bilateral choanal atresia, } \\
\text { GORD, episodes of } \\
\text { tachykardia and } \\
\text { bradycardia, dermoid } \\
\text { cyst at orbital roof/ } \\
\text { sphenoid wing }\end{array}$ \\
\hline
\end{tabular}

\begin{tabular}{l}
\hline Patient 2 \\
\hline 38 \\
2660 \\
Male \\
typical facial appearance \\
of RSTS \\
GORD, undescended \\
testes, laryngomalacia, \\
cataract, PDA
\end{tabular}

Patient 3

38

2985

Female

typical facial appearance of RSTS

Choanal stenosis, tricuspid atresia type $1 c$, short stature

$\begin{array}{ll}\text { Developmental delay } & \text { Yes } \\ & \\ \text { Age at diagnosis of RSTS } & 2.38 \text { years } \\ \text { Age at diagnosis of HH } & 1.54 \text { years } \\ \text { Metabolic profile during hypoglycaemia } \\ \text { Glucose, mmol/L } & 2.3 \\ \text { Insulin, pmol/L } & 27 \\ \text { C-peptide, pmol/L } & \mathrm{N} / \mathrm{A} \\ \text { Hypoketotic } & \text { Yes } \\ \text { Free Fatty acids } & \text { Low } \\ \text { Pathogenic mutation } & \text { Heterozygous de novo } \\ & \text { missense mutation } \\ & \text { c.3764A }>\mathrm{G}, \\ & \text { p.(His1255Arg) in EP300 }\end{array}$

Additional investigations related to $\mathrm{HH}$

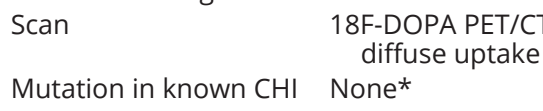

none specific

$12 \mathrm{mg} / \mathrm{kg} / \mathrm{min}$

Response unclear due to parental malcompliance

Unresponsive

DZX: fluid overload

None

Yes DZX: $7.5 \mathrm{mg} / \mathrm{kg} /$ day
DZX: fluid overload

Yes

Yes

Daytime bolus

Continuous overnight

4

Bolus PEG feed at bedtime

$11-15 \mathrm{~h}$

Patient 4

Female

partial facial appearance of RSTS

Bilateral choanal atresia, GORD, unilateral multicystic dysplastic kidney, ASD, dilatation of the asc. aorta, mild conductive hearing loss, recurrent small hymena cyst, query Müllerian anomaly

Moderate expressive speech delay

1.58 years

1.42 years

2.1

39

n.d.

Low

Heterozygous de novo missense mutation c.4783T>G, p.(Phe1595Val) in EP300

None*

n.d.

Responsive (10.6 mg/kg/day) day)

DZX: $6 \mathrm{mg} / \mathrm{kg} / \mathrm{day}$

*Including ABCC8, KCNJ11, GCK, GLUD1, HADH, HNF1A, HNF4A, SLC16A1, UCP2.

ASD, atrial septal defect; DZX, diazoxide; GORD, gastro-oesophageal reflux disease; NIF, nifedipine; OCT, octreotide; PDA, patent ductus arteriosus; PEG, percutaneous gastrostomy. 
showed normal intracranial appearances including the hypothalamic pituitary axis. A well-defined cystic lesion related to the left sphenoid wing or orbital roof, consistent with a dermoid cyst was seen. Electromyography and nerve conduction studies showed minor abnormalities of peripheral nerve conduction.

She had recurrent episodes of hypoglycaemia from the age of 1.5 years and had generalized tonic clonic seizures following an episode of hypoglycaemia. Further biochemical investigations confirmed the diagnosis of HH (Table 1). She was then commenced on diazoxide at the dose of $5 \mathrm{mg} / \mathrm{kg} /$ day and chlorothiazide $7 \mathrm{mg} / \mathrm{kg} / \mathrm{day}$. A percutaneous gastrostomy was also inserted, as part of the management of $\mathrm{HH}$, along with severe GORD and unsafe swallow. She was fed with frequent bolus feeds during the daytime and continuous gastrostomy feeds overnight. However, she continued to have episodes of hypoglycaemia and was transferred to a specialist centre for further management of $\mathrm{HH}$. Genetic testing was negative for known non-syndromic causes of $\mathrm{HH}$ (ABCC8, KCNJ11, GCK, GLUD1, HADH, HNF1A, HNF4A, SLC16A1). ${ }^{18} \mathrm{~F}$-DOPA-PET/CT scan suggested diffuse uptake of ${ }^{18} \mathrm{~F}$-DOPA. The patient was unresponsive to maximum doses of diazoxide, octreotide and nifedipine. She was tried on sirolimus (mTOR inhibitor) therapy (maximum $5 \mathrm{mg} / \mathrm{m}^{2} /$ day), to which she demonstrated a good response, but later developed severe systemic infection (sepsis). Consequently, sirolimus was stopped at the age of 2.6 years and she was managed with an intensive feeding regime. Thickened liquids and pureed food were gradually introduced into her diet.

This individual was recruited to the DDD project (20, 21) to try to understand the cause of her difficulties and a diagnosis of RSTS was made at 2.4 years following the identification of a likely pathogenic variant in EP300 c.3764A>G p.His1255Arg.

At her last clinic review at the age of 3.9 years she successfully tolerated 4-6hourly overnight gastrostomy feeds and on demand feeds during daytime (to provide adequate calories). Fasting test revealed a fasting tolerance of $11 \mathrm{~h}$ (blood glucose $2.9 \mathrm{mmol} / \mathrm{L}$, undetectable insulin $<14 \mathrm{pmol} / \mathrm{L})$.

\section{Case 2}

Individual 2 (P2) was born at 38 weeks gestation to nonconsanguineous parents with a birth weight of $2660 \mathrm{~g}$ ( -1.2 SDS). P2 was noticed to have poor feeding on day 1 of life and on day 2 he had a generalized seizure associated with low blood glucose of $0.9 \mathrm{mmol} / \mathrm{L}$. He was admitted to the neonatal unit and hypoglycaemia was managed by regular feeds and intravenous fluids. He was noted to have feeding difficulties, including choking episodes, leading to an apnoeic episode and was diagnosed with GORD and started on anti-reflux medications in the first week of life. Feeds were subsequently changed to an amino acid-based formula due to a family history of cow's milk protein intolerance.

He was also noted to have coarse facial features, broad and angulated thumbs and broad halluces. Other findings included bilateral undescended testes, mild laryngomalacia, left anterior polar cataract and a patent ductus arteriosus which closed spontaneously. Due to a history of seizure-like episodes, he had a brain MRI and CT, which showed some non-specific white matter changes and delayed myelination. Electroencephalogram (EEG) did not show the presence of epileptiform activity.

He continued to have intermittent episodes of hypoglycaemia and his hypoglycaemia screen showed hypoketotic $\mathrm{HH}$ (blood glucose $1.6 \mathrm{mmol} / \mathrm{L}$, insulin $36 \mathrm{pmol} / \mathrm{L}$, C-peptide $612 \mathrm{pmol} / \mathrm{L}$, negative urine ketones). He had high glucose requirements $(12 \mathrm{mg} / \mathrm{kg} /$ $\min$ ) in order to maintain euglycaemia. Subsequently, he was started on diazoxide on day 38, but this was stopped a few days later due to signs of fluid overload. On day 46 , the patient was transferred to a specialist centre for the management of $\mathrm{HH}$. He was managed on regular feeds and at the age of 2.5 months, he fasted for $6 \mathrm{~h}$ and was managed on regular high calorie feeds (blood glucose $4.2 \mathrm{mmol} / \mathrm{L}$, undetectable insulin $<14 \mathrm{pmol} / \mathrm{L}$ ). He had persistent vomiting on continuous feeds and video fluoroscopy showed poor suck and unsafe swallow. A barium study confirmed GORD and he underwent a Nissens fundoplication at 8 months of age. He developed post prandial hypoglycaemia with an inappropriate presence of insulin following OGTT (glucose $2.5 \mathrm{mmol} / \mathrm{L}$, insulin $78.5 \mathrm{pmol} / \mathrm{L}$ ). This suggested that the mechanism of his hypoglycaemia is related to surges in insulin secretion in response to glucose ingestion (carbohydrate containing meals). He was treated with continuous feeds via gastrostomy and slow bolus feeds.

He was given another trial of diazoxide (up to $10 \mathrm{mg} /$ $\mathrm{kg}$ /day) along with 2-hourly bolus feeds. However, he continued to have hypoglycaemic episodes and a decision was made to stop the diazoxide as parents were not keen to continue due to its side effects of hypertrichosis. He also had a trial of nifedipine but did not show any improvement in his blood glucose levels. He was then discharged home on 24-h continuous feeds. He was gradually tried on small bolus feeds at the age of 4.0 years 
and was commenced on acarbose $(25 \mathrm{mg}$ three times per day) with his bolus feeds. He is currently 7.87 years, on acarbose ( $25 \mathrm{mg}$ three times per day) and on demand feeding regime. He continues to have occasional episodes of post prandial hypoglycaemia with a good fasting tolerance of $18 \mathrm{~h}$ with no hypoglycaemia at the end of the fast (blood glucose $4.1 \mathrm{mmol} / \mathrm{L}$, undetectable insulin $<14 \mathrm{pmol} / \mathrm{L}, \quad$ FFA $1.06 \mathrm{mmol} / \mathrm{L}$, beta-hydroxybutyrate $1.17 \mathrm{mmol} / \mathrm{L})$.

His genetic investigations confirmed a heterozygous pathogenic variant c.1044delT, p.Glu349Lysfs*5 in CREBBP which confirmed the diagnosis of RSTS.

\section{Case 3}

The third individual (P3) was born at 38 weeks of gestation to healthy, non-consanguineous parents. Her birth weight was $2985 \mathrm{~g}$ (-0.45 SDS), length $47 \mathrm{~cm}(-1.48$ SDS) and head circumference $31.8 \mathrm{~cm}(-1.92 \mathrm{SDS})$. Cleft palate, dysmorphic features and central cyanosis were noted at birth requiring intensive care treatment. Further diagnostic evaluations revealed tricuspid atresia type Ic that was surgically managed, later resulting in Fontan circulation.

Since day 5 of life, recurrent hypoglycaemia was observed requiring $>8 \mathrm{mg} / \mathrm{kg} / \mathrm{min}$ carbohydrates. During hypoglycaemia $(<2.8 \mathrm{mmol} / \mathrm{L})$, repeated evaluations showed inappropriate insulin secretion (154 and $249 \mathrm{pmol} / \mathrm{L}$ ), suppressed ketones and low FFA, thus leading to the diagnosis of HH. At 6 weeks of age, diazoxide treatment $(<5 \mathrm{mg} / \mathrm{kg} /$ day $)$ was initiated leading to improved glycaemic control. However, for unclear reasons diazoxide was not titrated above $5 \mathrm{mg} /$ $\mathrm{kg} /$ day, although carbohydrate requirements were still increased. At hospital discharge at 6 months of age, $\mathrm{HH}$ was managed with low-dose diazoxide $(2.5 \mathrm{mg} / \mathrm{kg} / \mathrm{day})$, frequent daytime feeds and continuous percutaneous gastric tube (PEG) feeding overnight.

At first admission to a $\mathrm{HH}$ specialist service at 4.3 years, body weight was $13.3 \mathrm{~kg}$ (-1.79 SDS), length $90.4 \mathrm{~cm}$ $(-3.2$ SDS $)$ and head circumference $45.5 \mathrm{~cm}(-3.7 \mathrm{SDS})$. Facial features such as a beaked nose, arched eyebrows, long eyelashes, left ear auricular dysplasia, long philtrum with thin upper lip, ptosis, intermittent strabismus and choanal stenosis were noted, as well as coarse wrists and psychomotor difficulties. Glycaemic control was achieved by low-dose diazoxide treatment $(2.2 \mathrm{mg} / \mathrm{kg} /$ day) in addition to giving daytime meals every $4-5 \mathrm{~h}$ and continuous overnight feeding via PEG (stepwise decreased to $1.4 \mathrm{mg} / \mathrm{kg} / \mathrm{min}$ glucose). After pausing diazoxide for
7 days, formal testing revealed a fasting tolerance of less than $6 \mathrm{~h}$ (blood glucose $2.8 \mathrm{mmol} / \mathrm{L}$, insulin $26 \mathrm{pmol} / \mathrm{L}$, suppressed ketones and FFA). Therefore, diazoxide treatment was commenced again and gradually increased to $7.5 \mathrm{mg} / \mathrm{kg} /$ day, leading to stable blood glucose levels $>3.9 \mathrm{mmol} / \mathrm{L}$ and a fasting tolerance of $11-15 \mathrm{~h}$ without the need for further continuous overnight gastrostomy feeding.

NGS excluded disease-causing pathogenic variants in genes known to cause HH (ABCC8, ALG3, GCK, GLUD1, HADH, HK1, HNF1A, HNF4A, HRAS, INSR, KCNJ11, KCNQ1, KDM6A, KMT2D, MAFA, MPI, NSD1, PAX6, PGM1, PMM1, PMM2, SLC16A1, TRMT10A, UCP2) or cardiofaciocutaneous syndromes (BRAF, KRAS, NRAS, PTPN11, RAF1, RIT1, SOS1). Genetic testing of other syndromic conditions identified a heterozygous de novo missense variant in EP300 (c.4505C >T p.(Pro1502Leu)), classified as likely pathogenic according to ACMG criteria (18), confirming the diagnosis of Rubinstein-Taybi syndrome.

\section{Case 4}

The fourth individual (P4) has been described previously (16). She was born at 36 weeks of gestation to healthy, nonconsanguineous parents of English (mother) and Balkan (father) descent. Her birth weight was $2400 \mathrm{~g}$ (-0.79 SDS), length $48 \mathrm{~cm}(-0.15$ SDS) and head circumference $33 \mathrm{~cm}$ (-0.2 SDS). Bilateral choanal atresia required immediate intensive care treatment and nasal stenting at day 16 of life. Right multicystic dysplastic kidney had been diagnosed prenatally and the right kidney was later found to be non-functional. At day 8 of life, a small ostium secundum atrial septal defect and an isolated dilatation of the ascending aorta were diagnosed, not requiring treatment.

At 5 months of age, poor oral intake and GORD required the insertion of a percutaneous gastric tube. At around 1.0 year when weaning her off gastrostomy feeding, parents first noticed excessive sleepiness as well as an episode with eye twitching suggestive of a seizure. At 1.4 years an episode of jitteriness and decreased responsiveness following a delayed feed prompted further diagnostic evaluations. Recurrent episodes of hypoketotic hypoglycaemia with inappropriately high serum insulin concentrations $(39 \mathrm{pmol} / \mathrm{L}$ at blood glucose level of $2.1 \mathrm{mmol} / \mathrm{L}$ ) led to the diagnosis of HH. Diazoxide treatment was initiated $(10.6 \mathrm{mg} / \mathrm{kg} /$ day $)$ and improved glycaemic control. Fasting tolerance at that time was approximately 5-6h with no hypoglycaemia at the end of 
the fast. Facial features included down-slanting palpebral fissures and microretrognathia, while some of the classic features of RSTS were absent. At 4.0 years of age $\mathrm{HH}$ is still managed with diazoxide treatment $(6 \mathrm{mg} / \mathrm{kg} /$ day $)$ and a bolus gastrostomy feed at bedtime. P4 has not required dose increases of diazoxide as she has grown. Apart from mild-to-moderate expressive speech delay, cognitive and motor development is age-appropriate. Currently, at 4 years, height is $100 \mathrm{~cm}(-0.7$ SDS) and weight $15.8 \mathrm{~kg}$ (-0.18 SDS).

Genetic analysis revealed a heterozygous de novo missense variant in EP300 (c4783T>G p.(Phe1595Val)) (16), classified as likely pathogenic according to ACMG criteria (18).

\section{Discussion}

Recent advances in molecular genetic testing have enabled the identification of novel genes linked with $\mathrm{HH}$. To date, more than nine genes (ABCC8, KCNJ11, GCK, GLUD1, HADH, HNF1A, HNF4A, SLC16A1, UCP2) have been identified to be associated with monogenic congenital hyperinsulinism. However, in approximately 50\% of clinically diagnosed patients with $\mathrm{HH}$, genetic aetiology remains unknown, suggesting further unrecognised disease-associated genes $(22,23)$. The widespread availability of extended genetic testing has also facilitated the diagnosis of many individuals with syndromic conditions and an increased awareness of the association of HH with a number of these. BWS is a notable example but $\mathrm{HH}$ has also been reported as a feature in Sotos syndrome, Kabuki syndrome and others.

Early diagnosis of hypoglycaemia and appropriate treatment is essential to prevent neuroglycopenic brain damage $(3,5)$. This holds particularly true for patients with syndromic $\mathrm{HH}$, as these children may already have an increased risk of seizures and mental retardation (9). We here systematically review the metabolic phenotype and clinical course of four RSTS patients with persistent $\mathrm{HH}$.

Three of our four patients and one of the formerly reported individuals with RSTS and $\mathrm{HH}$ harbour a heterozygous disease-related variant in EP300 (15). This is noteworthy, as EP300 pathogenic variants only account for about $10 \%$ of RSTS patients and the clinical features are often more subtle compared to those with CREBBPassociated RSTS (11). Only one of our four patients (P2) harbours a heterozygous pathogenic variant in CREBBP which was associated with transient hyperinsulinism. However, he developed post prandial HH (dumping syndrome). A possible cause of his post prandial hypoglycaemia was Nissen fundoplication surgery that was carried out due to severe GORD and feeding difficulties. Genetic testing was not available for the patient with transient HH and RSTS reported by Wyatt et al. (17). P2 and P3 exhibited typical clinical features suggestive of RSTS. Three of our patients were found to have choanal atresia or stenosis, which is not a commonly reported feature in RSTS.

Age at diagnosis of $\mathrm{HH}$ varied from day 1 and 5 of age in P2 and P3, respectively, to approximately 18 months of life in P1 and P4. The response to diazoxide treatment was variable. P1 was unresponsive to diazoxide, octreotide and nifedipine. This patient responded to sirolimus, but was ultimately managed with an intensive feeding regime due to sirolimus-associated sepsis. In contrast, P3 and P4 showed good response to diazoxide $(5-10 \mathrm{mg} / \mathrm{kg} / \mathrm{day})$. In P2 there was an initial diazoxide response but this could not be assessed fully due to fluid overload. Subsequently diazoxide was trialled for dumping syndrome but was stopped after $10 \mathrm{mg} / \mathrm{kg} /$ day due to parental anxiety of its side effects. The patient reported by Wyatt et al. was responsive to moderate doses of diazoxide $(10.9 \mathrm{mg} / \mathrm{kg} /$ day $)$ that could already be discontinued after 14 days of treatment (17). All of our patients additionally required continuous gastrostomy feeding. At the age of now 4.8 years and 4 years $\mathrm{P} 3$ and $\mathrm{P} 4$ still require moderate doses of diazoxide $(7.5 \mathrm{mg} / \mathrm{kg} / \mathrm{day}$ and $6 \mathrm{mg} / \mathrm{kg} / \mathrm{day}$, respectively), while P1 and P2, aged 3.9 years and 7.9 years, maintain euglycaemic via overnight gastrostomy feeds (P1) or on demand feeds and acarbose (P2).

Given the rarity of both RSTS (1:125 000) and HH $(1: 40000-50000)(15,24)$, the finding of at least four patients each suffering from both conditions clearly exceeds the expected frequency if both diagnoses were not linked in any way. However, the molecular mechanism underlying the association of HH with RSTS remains elusive. EP30O and CREBBP are ubiquitously expressed and highly homologous genes, sharing $>60 \%$ of protein sequence identity. They act as transcriptional co-activators with histone acetyltransferase activity. The EP300 and CREBBP genes encode P300 and CBP, respectively, which hold similar functions in chromatin remodelling and are believed to participate in the activities of several different transcription factors (25). The molecular mechanism of RSTS therefore appears to be a global transcriptional disturbance due to defective genome-wide histone modification (26). Both P300 and CBP are required for normal pancreatic islet development, beta cell function and survival. However, mice lacking P300 or CBP in 
pancreatic islets have reduced alpha and beta cell mass and become glucose intolerant due to hypoinsulinaemia (25). These findings in mice appear somehow contradictory to our observations. In all our patients hypoglycaemic episodes were associated with inadequately elevated levels of insulin strongly suggesting a mechanistic link. However, whether hyperinsulinism results from beta cell intrinsic pathways or from other factors such as paracrine glucagon signalling remains elusive. Since Crebbp- and Ep300-knockout mice both develop hypoinsulinaemia, overt or subclinical hyperinsulinism theroretically may progress to hypoinsulinism and glucose intolerance in RSTS patients. Clearly, additional mechanistic studies are required to elucidate the role of beta cell- and alpha cellsignalling in CREBBP- and EP3OO-associated $\mathrm{HH}$.

In conclusion, although three of our four patients harbour a pathogenic variant in EP300 rather than $C R E B B P$, a definite genotype-phenotype correlation with respect to age at onset of $\mathrm{HH}$ and diazoxide responsiveness cannot be drawn from our data, due to small sample size. However, our report identifies persistent $\mathrm{HH}$ as a novel association of RSTS and expands the spectrum of HH syndromes. Our observations emphasize the need to carefully screen RSTS patients for hypoglycaemia, particularly those presenting with seizures or unspecific symptoms, to ensure early recognition of $\mathrm{HH}$ and the initiation of appropriate treatment. We furthermore recommend to include $E P 300$ and $C R E B B P$ in the genetic testing for patients with syndromic $\mathrm{HH}$ and clinical features suggestive for Rubinstein-Taybi syndrome.

\section{Declaration of interest}

The authors declare that there is no conflict of interest that could be perceived as prejudicing the impartiality of this study.

\section{Funding}

The DDD study presents independent research commissioned by the Health Innovation Challenge Fund (grant number HICF-1009-003), a parallel funding partnership between Wellcome and the Department of Health and the Wellcome Sanger Institute (grant number WT098051). The views expressed in this publication are those of the author(s) and not necessarily those of Wellcome of the Department of Health. The study has UK Research Ethics Committee approval (10/H0305/83, granted by the Cambridge South REC, and GEN/284/12 granted by the Republic of Ireland REC). The research team acknowledges the support of the National Institute for Health Research, through the Comprehensive Clinical Research Network. This study makes use of DECIPHER, which is funded by the Wellcome.

\section{Author contribution statement}

A Welters, R El-Khairi, P Shah and S Kummer: These authors contributed equally to this work as shared first authors and shared senior authors.

\section{Acknowledgments}

The authors would like to thank all family members for their valuable cooperation and allowing us to share their cases. We thank Julie Raskin (Congenital Hyperinsulinism International) for connecting us with one of the four patients reported here.

\section{References}

1 Rozenkova K, Guemes M, Shah P \& Hussain K. The diagnosis and management of hyperinsulinaemic hypoglycaemia. Journal of Clinical Research in Pediatric Endocrinology 20157 86-97. (https://doi. org/10.4274/jcrpe.1891)

2 Shah P, Rahman SA, Demirbilek H, Guemes M \& Hussain K. Hyperinsulinaemic hypoglycaemia in children and adults. Lancet: Diabetes and Endocrinology 20175 729-742. (https://doi.org/10.1016/ S2213-8587(16)30323-0)

3 Helleskov A, Melikyan M, Globa E, Shcherderkina I, Poertner F, Larsen AM, Filipsen K, Brusgaard K, Christiansen CD, Hansen LK et al. Both low blood glucose and insufficient treatment confer risk of neurodevelopmental impairment in congenital hyperinsulinism: a multinational cohort study. Frontiers in Endocrinology 20178156. (https://doi.org/10.3389/fendo.2017.00156)

4 Meissner T, Wendel U, Burgard P, Schaetzle S \& Mayatepek E. Longterm follow-up of 114 patients with congenital hyperinsulinism. European Journal of Endocrinology 2003149 43-51. (https://doi. org/10.1530/eje.0.1490043)

5 Muukkonen L, Mannisto J, Jaaskelainen J, Hannonen R \& Huopio H. The effect of hypoglycaemia on neurocognitive outcome in children and adolescents with transient or persistent congenital hyperinsulinism. Developmental Medicine and Child Neurology 201961 451-457. (https://doi.org/10.1111/dmcn.14039)

6 Demirbilek H \& Hussain K. Congenital hyperinsulinism: diagnosis and treatment update. Journal of Clinical Research in Pediatric Endocrinology 20179 (Supplement 2) 69-87. (https://doi.org/10.4274/ jcrpe.2017.S007)

7 Galcheva S, Al-Khawaga S \& Hussain K. Diagnosis and management of hyperinsulinaemic hypoglycaemia. Best Practice and Research: Clinical Endocrinology and Metabolism 201832 551-573. (https://doi. org/10.1016/j.beem.2018.05.014)

8 Kalish JM, Boodhansingh KE, Bhatti TR, Ganguly A, Conlin LK, Becker SA, Givler S, Mighion L, Palladino AA, Adzick NS et al. Congenital hyperinsulinism in children with paternal 11p uniparental isodisomy and Beckwith-Wiedemann syndrome. Journal of Medical Genetics 201653 53-61. (https://doi.org/10.1136/ jmedgenet-2015-103394)

9 Kapoor RR, James C \& Hussain K. Hyperinsulinism in developmental syndromes. Endocrine Development 200914 95-113. (https://doi. org/10.1159/000207480)

10 Mohamed Z, Arya VB \& Hussain K. Hyperinsulinaemic hypoglycaemia: genetic mechanisms, diagnosis and management. Journal of Clinical Research in Pediatric Endocrinology 20124 169-181. (https://doi.org/10.4274/jcrpe.821)

11 Fergelot P, Van Belzen M, Van Gils J, Afenjar A, Armour CM, Arveiler B, Beets L, Burglen L, Busa T, Collet M et al. Phenotype and genotype in 52 patients with Rubinstein-Taybi syndrome caused by EP300 mutations. American Journal of Medical Genetics: Part A 2016 170 3069-3082. (https://doi.org/10.1002/ajmg.a.37940)

12 Petrij F, Giles RH, Dauwerse HG, Saris JJ, Hennekam RC, Masuno M, Tommerup N, van Ommen GJ, Goodman RH \& Peters DJ. Rubinstein-Taybi syndrome caused by mutations in the transcriptional co-activator CBP. Nature 1995376 348-351. (https:// doi.org/10.1038/376348a0)

13 Roelfsema JH, White SJ, Ariyurek Y, Bartholdi D, Niedrist D, Papadia F, Bacino CA, den Dunnen JT, van Ommen GJ, Breuning MH 
et al. Genetic heterogeneity in Rubinstein-Taybi syndrome: mutations in both the CBP and EP300 genes cause disease. American Journal of Human Genetics 200576 572-580. (https://doi. org/10.1086/429130)

14 Wincent J, Luthman A, van Belzen M, van der Lans C, Albert J, Nordgren A \& Anderlid BM. CREBBP and EP300 mutational spectrum and clinical presentations in a cohort of Swedish patients with Rubinstein-Taybi syndrome. Molecular Genetics and Genomic Medicine 20164 39-45. (https://doi.org/10.1002/mgg3.177)

15 Lopez M, Garcia-Oguiza A, Armstrong J, Garcia-Cobaleda I, GarciaMinaur S, Santos-Simarro F, Seidel V \& Dominguez-Garrido E. Rubinstein-Taybi 2 associated to novel EP300 mutations: deepening the clinical and genetic spectrum. BMC Medical Genetics 20181936. (https://doi.org/10.1186/s12881-018-0548-2)

16 Costain G, Kannu P \& Bowdin S. Genome-wide sequencing expands the phenotypic spectrum of EP300 variants. European Journal of Medical Genetics 201861 125-129. (https://doi.org/10.1016/j. ejmg.2017.11.002)

17 Wyatt D. Transient hypoglycemia with hyperinsulinemia in a newborn infant with Rubinstein-Taybi syndrome. American Journal of Medical Genetics 199037 103-105. (https://doi.org/10.1002/ ajmg.1320370124)

18 Richards S, Aziz N, Bale S, Bick D, Das S, Gastier-Foster J, Grody WW, Hegde M, Lyon E, Spector E et al. Standards and guidelines for the interpretation of sequence variants: a joint consensus recommendation of the American College of Medical Genetics and Genomics and the Association for Molecular Pathology. Genetics in Medicine 201517 405-424. (https://doi.org/10.1038/gim.2015.30)

19 Ferrara C, Patel P, Becker S, Stanley CA \& Kelly A. Biomarkers of insulin for the diagnosis of hyperinsulinemic hypoglycemia in infants and children. Journal of Pediatrics 2016168 212-219. (https:// doi.org/10.1016/j.jpeds.2015.09.045)

20 Wright CF, Fitzgerald TW, Jones WD, Clayton S, McRae JF, van Kogelenberg M, King DA, Ambridge K, Barrett DM, Bayzetinova T et al. Genetic diagnosis of developmental disorders in the DDD study: a scalable analysis of genome-wide research data. Lancet 2015385 1305-1314. (https://doi.org/10.1016/S01406736(14)61705-0)

21 Deciphering Developmental Disorders Study. Large-scale discovery of novel genetic causes of developmental disorders. Nature $2015 \mathbf{5 1 9}$ 223-228. (https://doi.org/10.1038/nature14135)

22 Kapoor RR, Flanagan SE, Arya VB, Shield JP, Ellard S \& Hussain K. Clinical and molecular characterisation of 300 patients with congenital hyperinsulinism. European Journal of Endocrinology 2013 168 557-564. (https://doi.org/10.1530/EJE-12-0673)

23 Snider KE, Becker S, Boyajian L, Shyng SL, MacMullen C, Hughes N, Ganapathy K, Bhatti T, Stanley CA \& Ganguly A. Genotype and phenotype correlations in 417 children with congenital hyperinsulinism. Journal of Clinical Endocrinology and Metabolism 201398 E355-E363. (https://doi.org/10.1210/jc.2012-2169)

24 Stanley CA. Perspective on the genetics and diagnosis of congenital hyperinsulinism disorders. Journal of Clinical Endocrinology and Metabolism 2016101 815-826. (https://doi.org/10.1210/jc.2015-3651)

25 Wong CK, Wade-Vallance AK, Luciani DS, Brindle PK, Lynn FC \& Gibson WT. The p300 and CBP transcriptional coactivators are required for beta-cell and alpha-cell proliferation. Diabetes 201867 412-422. (https://doi.org/10.2337/db17-0237)

26 Izumi K. Disorders of transcriptional regulation: an emerging category of multiple malformation syndromes. Molecular Syndromology 20167 262-273. (https://doi.org/10.1159/000448747)

Received 21 February 2019

Revised version received 17 April 2019

Accepted 26 April 2019 